\title{
BIOTIN ASSAY WITH A COCCUS, MICROCOCCUS SODONENSIS, NOV. SP.
}

\author{
SHELDON AARONSON ${ }^{1}$ \\ Haskins Laboratories, New York, New York \\ Received for publication June 16, 1954
}

A gram positive, tetrad forming coccus was isolated by Dr. Alice Bicknell of Michigan State College from a fresh water lake in Michigan at a depth of 6 meters. The low concentration of organic nutrients in this environment suggested that the coccus might respond sensitively to required organic nutrients. This coccus is a sensitive assay organism for free biotin and closely related compounds.

\section{MATERIALS AND METHODS}

Cultures were maintained on nutrient agar. The techniques for determining nutritional requirements were essentially those used by Baker, Sobotka, and Hutner (1953). The inoculum for vitamin experiments was prepared by growing the bacteria in a chemically defined medium with minimal amounts of biotin. Growth was measured as optical density with the Welch densichron.

\section{RESULTS}

Description of the organism. The coccus Micrococcus sodonensis, nov. sp., has the following characteristics: Spheres: 0.8-1.5 microns; occurring singly, in pairs, and in groups of four. Nonmotile, nonsporeforming, and gram positive. Gelatin stab: No liquefaction. Agar slant: Abundant, yellow, shiny, butyrous. Broth: Turbid with sediment. Indole not formed. Nitrates not reduced. Hydrogen sulfide (lead acetate agar) not formed. Starch not hydrolyzed. No change in brom cresol purple milk. Growth in Koser's citrate broth when biotin added. No gas and acid from glucose, lactose, sucrose, maltose, mannitol. Aerobic. Optimal temperature, 35 C. Source: Fresh water lake.

Nutritional requirements. The minimal nutritional requirements of Micrococcus sodonensis are presented in table 1. Growth was not further enhanced by the addition of a tryptic digest of casein or yeast autolysate. The coccus grew in

\footnotetext{
1 Taken in part from a dissertation presented in partial fulfillment of the requirements for the Ph.D. in Biology at New York University.
}

the $\mathrm{pH}$ range 6.0-9.0 with optimal growth at $\mathrm{pH}$ 7.0. The temperature range was $22-37 \mathrm{C}$ with the optimum at $35 \mathrm{C}$.

DL-Lactate, DL-malate, or L-glutamate was utilized as substrate, while sorbitol, mannitol, glycerol, or gluconate had no effect. Although glycerol was not utilized, $\mathrm{K}$ glycerophosphate was incorporated in the medium as a carrier for phosphate in place of inorganic phosphate compounds since it minimized precipitation. Growth was best with a combination of DL-lactate and Lglutamate (table 1). Besides a substrate, biotin was the only other organic requirement. This biotin requirement was also satisfied by desthiobiotin or biocytin ${ }^{2}$ (figure 1). Biocytin was about 65 per cent more effective than biotin or desthiobiotin on a molar basis. Approximately $1,000 \times$ (by weight) of "tween 80 " or $\mathrm{Na}$ oleate also satisfied the biotin requirement. DL-Aspartate, alone or in combination with "tween 80", did not replace or spare biotin.

\section{DISCUSSION}

The outstanding features of the coccus described are its yellow color and its ability to form groups of four. Comparison of the growth characteristics of this coccus with the descriptions of the Micrococcaceae (Breed et al., 1948) suggested that it belonged to the genus Micrococcus. It was compared with species of the genus Micrococcus which form a yellow pigment, i.e., $M$. luteus, $M$. flavus, $M$. citreus, etc., and was found to resemble none of these since they all produce acid from one or more carbohydrates while the new coccus does not. In addition, none of the above micrococci forms groups of four.

The genus Gafflya was ruled out because parasitism is a major diagnostic criterion, and the new coccus was not found on any host organism. Furthermore, Gaffleya tetragena, while producing yellow variants and tetrads, also produces acid from glucose and lactose, while the new coccus produces no acid from these carbohydrates.

2 Biocytin was obtained through the generosity of Dr. L. D. Wright of Sharp and Dohme, Inc. 
TABLE 1

Chemically defined medium for Micrococcus sodonensis

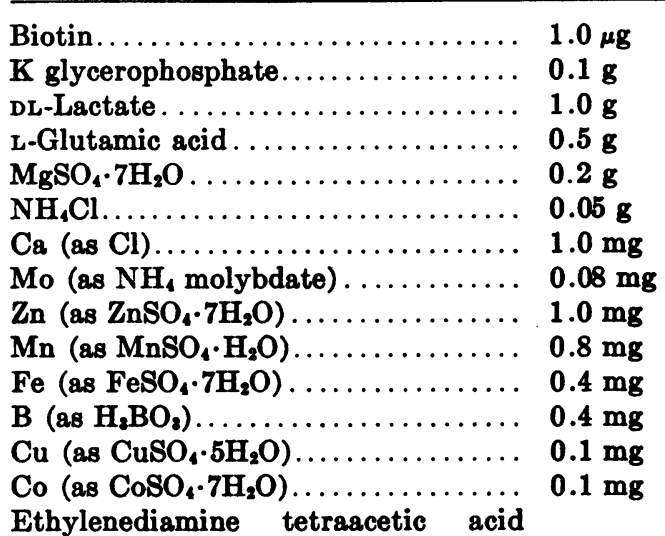

(EDTA) .................. $0.05 \mathrm{~g}$

Distilled water................. to $100 \mathrm{ml}$

$\mathrm{pH} 7.0$

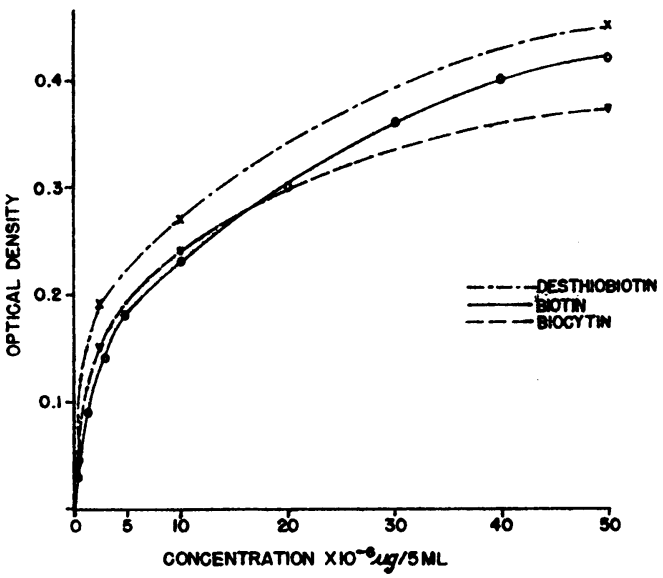

Figure 1. Utilization of biotin and related compounds by Micrococcus sodonensis.

Within the genus Sarcina there are yellow pigmented species, i.e., S. lutea, S. flava, S. aurantiaca, etc. S. lutea, S. flava, and S. aurantiaca liquefy gelatin while the new coccus does not. It also differs from $S$. citrea in not being motile. Since the new coccus fitted none of the species of Micrococcaceae and resembled the genus Micrococcus most closely, the formation of a new species seemed justifiable, and this coccus is designated Micrococcus sodonensis, after Lake Sodon, Michigan, where it was isolated.

The simple nutritional requirements of $M$. sodonensis and its great sensitivity to biotin and related compounds suggest its usefulness as an assay organism. As little as $1 \times 10^{-6} \mu \mathrm{g}$ per $\mathrm{ml}$ of biotin was detectable (figure 1). The Lactobacillus arabinosus assay of Wright and Skeggs (1944) recommended in Methods of Vitamin Assay (1951) is sensitive to approximately $4 \times 10^{-4} \mu \mathrm{g}$ per ml. The medium for $L$. arabinosus is far more complex than that for Sarcina sodensis. Furthermore, $L$. arabinosus does not respond to desthiobiotin (Lilly and Leonian, 1944) or biocytin (Wright et al., 1951a). M. sodonensis responds to both these compounds and thus appears to offer a more comprehensive assay of low molecular biotin compounds. It does not, however, respond to biotin bound with egg white.

Wright et al. (1951b) reported that biocytin, biotinamide, N-biotinyl-p-aminobenzoic acid, and $\mathrm{N}$-biotinyl- $\beta$-alanine were equivalent to biotin for several microorganisms. Biocytin was also approximately equivalent to biotin in stimulating the aspartic acid deaminase system of Proteus vulgaris (Wright et al., 1952). It thus appears that several microorganisms can obtain their required biotin from complex derivatives. The more efficient response of $M$. sodonensis to biocytin than to biotin on a molar basis suggests that biocytin may be closer to the unknown coenzyme form of biotin.

The organism has been deposited in the American Type Culture Collection.

\section{ACRNOWLFDGMFNTS}

The author wishes to express his gratitude to Professor R. F. Nigrelli of New York University for his encouragement and guidance.

\section{SUMMARY}

The characteristics of Micrococcus sodonensis, nov. sp., have been studied. The species is useful for the assay of biotin and similar compounds because of its sensitivity $\left(1 \times 10^{-6} \mu \mathrm{g}\right.$ per $\left.\mathrm{ml}\right)$ and its simple nutritional requirements. The organism responds more efficiently to biocytin than other derivatives of biotin.

\section{REFERENCES}

Bakger, H., Sobotra, H., and Hutner, S. H. 1953 Growth requirements of some thermophilic and mesophilic bacilli. J. Gen. Microbiol., 9, 485-493.

Breed, R. S., Murray, E. G. D., and Hitchens, A. P. 1948 Bergey's manual of determinative bacteriology. 6th ed. The Williams and Wilkins Co., Baltimore, Maryland. 
Lilly, V. G., and Leonian, L. H. 1944 The anti-biotin effect of desthiobiotin. Science, 99, 205-206.

Methods of vitamin assay. Prepared and edited by the Association of Vitamin Chemists, Inc. 2nd ed. 1951 Interscience Publishers, Inc., New York.

Wright, L. D., and Skegas, H. R. 1944 Determination of biotin with Lactobacillus arabinosus. Proc. Soc. Exptl. Biol. Med., 66, 95-98.
Wright, L. D., Skfgas, H. R., and Cresson, E. L. 1951a The elucidation of biocytin. Science, 114, 635-636.

Wright, L. D., Skeggs, H. R., and Cresson, E. L. $1951 b$ Amides and amino acid derivatives of biotin: microbiological studies. J. Am. Chem. Soc., 73, 4144-4145.

Wright, L. D., Bkeggs, H. R., and Cresson, E. L. 1952 Biological studies of biocytin. J. Am. Chem. Soc., 74, 2004-2006. 